\title{
The Effect of a Computer Instructional Model in Bringing about a Conceptual Change in Students' Understanding of Particulate Concepts of Gas
}

\author{
Bao-tyan Hwang and Shang-feng Chiu \\ National Taiwan Normal University, Taiwan, ROC \\ Chefv006@scc.ntnu.edu.tw s42190@cc.btby.edy.tw
}

\begin{abstract}
This study explores students' misconceptions with the particulate concept of matter in gaseous state. Then, based on promoting students' learning and understanding from a constructivist perspective, the effectiveness of instructional activities by presenting a demonstration with computer simulation was investigated. Students were expected to benefit from computer monitored instruction in a number of ways: by becoming more interested in physical phenomena and therefore more motivated; by acquiring a concrete example of a abstract concept that will aid them in reasoning; and by being able to evaluate their predictions of a future physical event using their current conceptual framework and the new concept being presented in the teaching activity. A systematic study of students' ideas on particulate concepts was carried out first with the participation of 296 subjects in Grade 5-8 (age 11-12 through 14-15) in Taiwan. An open-ended questionnaire and picture drawing question was administered to the subjects. The responses were categorized according to the level of sophistication of the answer and the drawing of the picture. The instruments used both in the pretest and posttest were designed in a format of a two-tier test. Teaching is conducted by a computer demonstration that was specifically designed from implications regarding students' cognitive conflict. The research findings indicated that students had some misconceptions about the gaseous particles concerning the size, weight, motion and kinetic distribution in space. After teaching, there was a comparison of students' learning outcomes between the pretest and posttest. A significant difference statistically revealed that teaching activity in this research by the computer-simulated demonstration could obviously benefit students' conceptual change in learning of particulate theory.
\end{abstract}

Keywords: computer simulated demonstration, particulate concepts, diagnostic drawing test, conceptual change, cognitive conflict

\section{Introduction}

This study is part of a research project, which was conducted with funds provided by National Science Council in Taiwan. It was designed to study knowledge acquisition processes in science

Material published as part of these proceedings, either on-line or in print, is copyrighted by Informing Science. Permission to make digital or paper copy of part or all of these works for personal or classroom use is granted without fee provided that the copies are not made or distributed for profit or commercial advantage AND that copies 1) bear this notice in full and 2) give the full citation on the first page. It is permissible to abstract these works so long as credit is given. To copy in all other cases or to republish or to post on a server or to redistribute to lists requires specific permission from the publisher at Publisher@InformingScience.org domains through a variety of teaching strategies in elementary and secondary school students. In this study, the specific domain chosen to investigate the general issues is the particulate conceptions of gases.

In a beginning chemistry class, the problems that high school students 
experience with the concepts such as "atom," "molecule," "element," "compound," and "chemical or physical phenomenon of a gas." have been well documented. The main reason is that students have not handled or even seen the particles involved. According to Piaget, the particulate concept is classified as stage of formal operations, and a student should enter the formal operational stage at about age 11 and essentially complete basic intellectual development of age 15 (Flavell, 1963). These difficulties have usually been ascribed to students' lack of formal operational ability, and various instructional interventions have been designed to reduce formal reasoning requirements, with limited success.

Using a conventional science test to determine students' misconceptions might be problematic. Students may answer questions correctly for the wrong reasons. Therefore, in this study, a type of alternative evaluation by individualized demonstration test was designed. When students' exhibited specific misconceptions, their picture drawing, answers and reasoning were all evaluated.

Although there are a few research investigations that have described students' misconceptions about particulate concepts (Benson, 1993; Borghi, Ambrosis, Massara, Grossi, \& Zoppi 1988; Furio, Perez, \& Harris, 1987; Gabel, Samuel, \& Hunn, 1987; Griffiths, \& Preston, 1992; Hwang, 1998; Johnson, 1998a, 1998b; Newton, 1999; Novick, \& Nussbaum, 1978, 1981; Nussbaum, 1997; Stavy, 1988; Tytler, 1998), there has been no attempt to develop a theory based teaching software about particulate concept that is readily available to teachers.

Many research findings concerning teaching with a computer indicated a positive conclusion. For approaching the teaching goals, monitored computer teaching is based on learning theory and provides students with an inqury learning environment. This kind of teaching can offer teachers a simulated condition and also can reinforce students' motivation of learning (Alessi, \& Trollip, 1991; Dexter, Anderson, \& Becker, 1999; Gagne, Wager, \& Rojas, 1981; Iding, 2000; Krendl, \& Lieberman, 1988; Mayer, 1999; Mayer, \& Moreno, 1998; Rieber, 1996; Williamson, \& Abraham, 1995).

The first hypothesis in this study was that high school students'difficulties with the particulate concepts were already generated in daily-life and held in mind but substantially different from scientists' views. And the second, if the students could be led to generate a more appropriate general concept, they would then experience far less difficulty with this abstract concept.

According to students' misconceptions, modelling the teaching of particulate concepts against daily-life experiences and identifying a series of contexts that relate to concepts being taught are important aspects of teaching strategy in this study. For helping students to think well, two general kinds of interventions by computer demonstration have been considered. One, reduce the level of thinking required of the learner by explaining the concept in some concrete manner or by providing students with some explicit problem solving techniques, and two, improve the students' formal operational thinking abilities through a formal reasoning training program. Considerably more attention has been directed toward the first approach in teaching design of computer simulation in this research.

\section{Purpose of the Study}

The purpose of this research was to diagnose particulate conceptions that students used when solving problems related to the chemical and physical phenomenon of a gas. The research was also conducted in order to investigate students' conceptions of gas after teaching them through designed software with computer simulated demonstration. In particular, five research purposes were addressed: (1) What is the students spontaneously constructed or naïve understanding of the particulate nature of gas prior to any formal instruction in the domain? (2) What is the students' understanding about the nature of gas particles, such as size, mass, in relation to temperature change? 
(3) What are the students' conceptions about the kinetic motion of gas particles at different temperatures? (4) What are the categories of students' particulate concepts associated with their reasoning? (5) What is the effect on students' conceptual changes of particulate before and after teaching through a teaching strategy of using computer simulated demonstration program?

\section{Methods}

The research methodology of this study is a kind of ONE-GROUP PRE-TEST AND POST-TEST DESIGN. Pre-test and post-tests were employed to provide representations of students' knowledge structure of particulate and relevant concepts. Units of teaching activity were administered in each section between pre-test and post-test. A demonstration teaching courseware with computer simulation, which was specifically designed from implications suggested by Rowell and Dawson (1981) regarding the teaching strategy of cognitive conflict, was used in this activity to teach concepts of gas particles and related pedagogy in a four week period. All these tests were in the format of teacher's demonstration with real daily-life materials and with a section of computer simulation, then students drew the picture and wrote the answers and reasons in a two-tier question sheet.

\section{Procedure}

In this study, the procedure involved first making students aware of the states of physical phenomenon for this experiment as well as doing demonstrations regarding particulate conceptions by teacher and with a computer simulation process. Then students' answers were collected, and their misconceptions were diagnosed. An interview technique with demonstration by real apparatus was the main method used for diagnosing students' particulate misconception. Detailed student interviews were interpreted using a framework from Piaget's cognitive development and ontological perspectives. Then an individualized demonstration test was first conducted by a pretest to each student each time, four weeks later, after a treatment of teaching with software of simulated demonstration based on students' cognitive conflict, a post-test was followed. In pretest, a series of event involving weight, motion, number of particles, temperature effect, and distribution of gaseous particles in a bottle were shown to students in a one-to-one situation. Familiar daily-life material was used to demonstrate the phenomena, e.g., in pre-test, a syringe used for motion of air particle. In the post-test, two bottles connected with a plastic tube were used for students' application of particle motion. For each event in these two tests, students were asked to describe and write down in the answer sheet what he or she saw happening, and then students were asked to explain what had happened by his or her view.

\section{Subjects}

The pre-test and post-test related to particulate concepts was administered to 296 students enrolled in elementary schools and junior high schools in Taiwan. Students were randomly selected from a range of classroom. The sample consisted of 148 male, and 148 female students. The composition of the sample by grade was 72 fifth-grade, 72 sixth-grade, 76 seventh-grade, and 76 eighth-grade students. Comparisons with conceptions of particle theory in pretest and post-test have therefore been made between students among grade 5 , grade 6 , grade 7 and grade 8 .

\section{Instruments}

A drawing and two-tier test of particulate concept was constructed to test misconception concerning related particulate concepts. And a cognitive conflict and conceptual change teaching unit was developed to stimulate students to gennerate modifications of their own misconception. 


\section{Main Concepts in the tests}

Theme topics in both the pre-test and post-test are as following, and the content of the tests are as shown in Table 1:

- The nature of particles

- The distribution of air particles

- The dynamic motion of gas particles

- The number conservation of gases

- The temperature effect on gas particles

- The gas pressure concept

Table 1 The main concepts in pre-test and post-test

\begin{tabular}{|l|l|}
\hline \multicolumn{1}{|c|}{ MAIN CONCEPTION } & \multicolumn{1}{c|}{ CONTENTS } \\
\hline 1.Nature of particulate & Particulate nature concepts (by drawing) \\
\cline { 2 - 3 } & The distribution of gaseous particles in different containers \\
\hline 2.Particles in a mixture & Particulate concept in the mixture of two gases \\
\hline 3.Distribution of air in a closed system & $\begin{array}{l}\text { The distribution of gas particles as space changed } \\
\text { The distribution of gas particles as the number of particles was changed } \\
\text { The effect of temperature on the distribution of particles in a container }\end{array}$ \\
\hline 4.Kinetic motion of particles & The states of particle motion in a container \\
\hline 5.Number conservation of particles & The number conservation of particles in different physical states \\
\hline 6.Size conservation of each particulate & The size conservation of each particle in different physical states \\
\hline 7.Effect of temperature on particle behavior & Temperature change and the state of particles \\
\hline 8.Pressure and particulate & The change of temperature on pressure of gas particles \\
\cline { 2 - 2 } & The change of space on pressure of gas \\
\hline
\end{tabular}

\section{The TEACHING ACTIVITY: CSDTP (The Computer Simulated Demon- stration for Teaching Particulate Concepts)}

The units of teaching activity in this computer program were designed around a cognitive development philosophy and focus on helping students develop conceptual understandings of the particulate conceptions. Based on cognitive conflict strategy, the authors have developed five teaching units of courseware with simulated demonstration design for the teaching of particulate concepts.

Unit 1: One particle at constant volume and constant temperature state. (Figure 1)

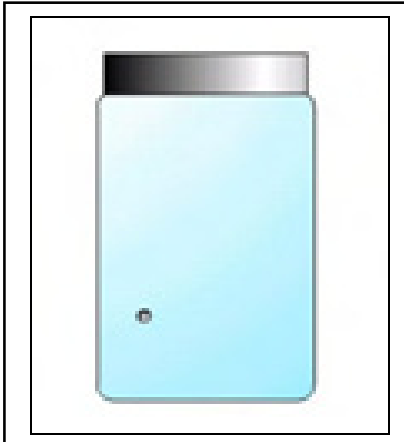

Figure 1. Simulation of one particle motion 
Unit 2: Constant number of particles at constant volume and different temperature conditions. (Figure 2)

Unit 3: Constant number of particles with a volume change in a static closed system. (Figure 3)
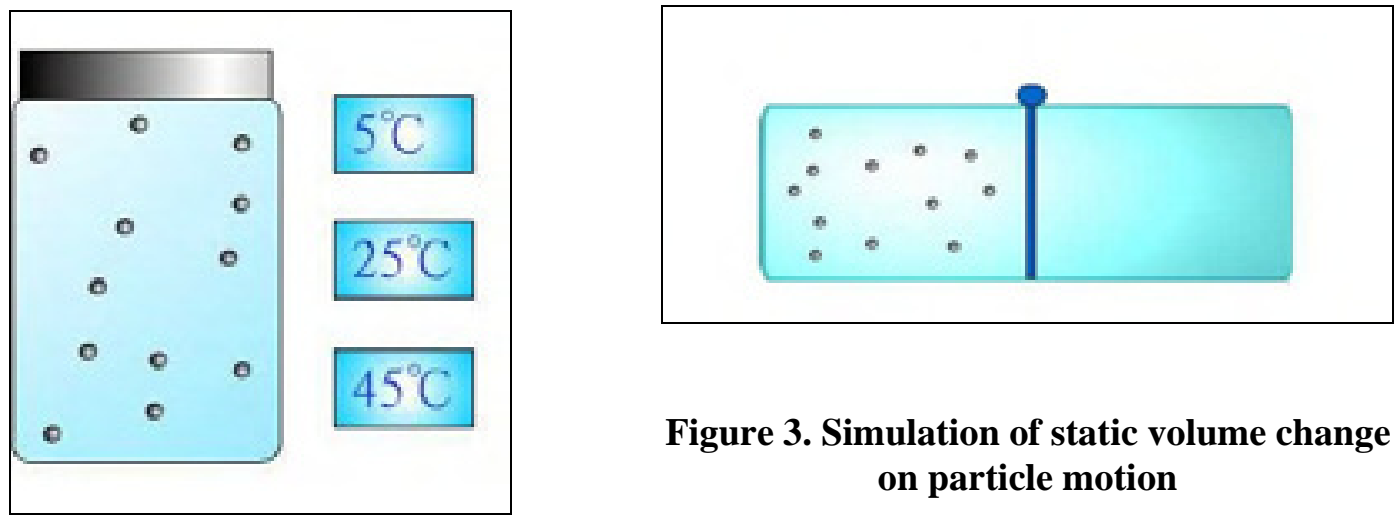

Figure 3. Simulation of static volume change on particle motion

Figure 2. Simulation of temperature on particle motion

Unit 4: Constant number of particles with a volume change in a dynamic closed system. (Figure 4) Unit 5: Two kinds of gas particles in a static closed system. (Figure 5)

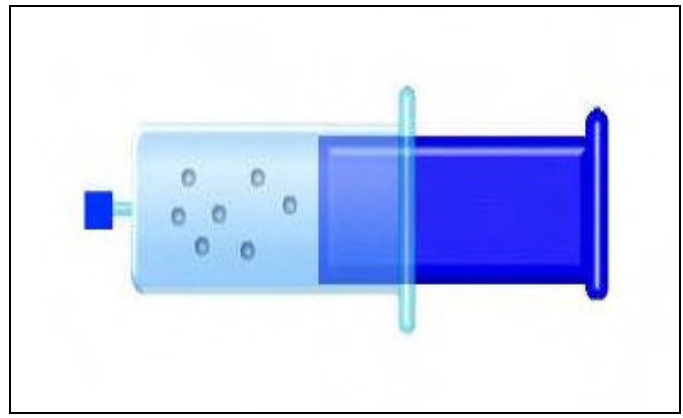

Figure 4. Simulation of dynamic volume change on particle motion

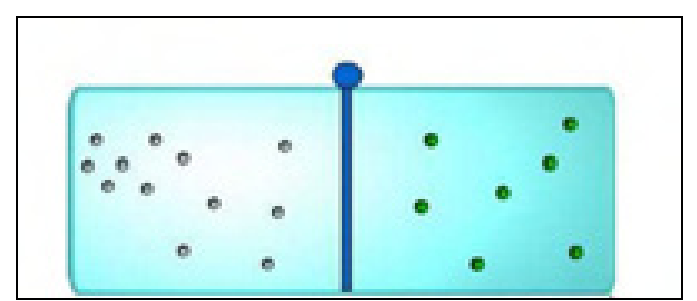

Figure 5. Application of particle motions with two different kinds of particles as volume changed

In this study we used Macromedia FLASH 5.0 for designing the whole courseware, because this program is easy for writing a common EXE and SWF files for Windows. Therefore, there are no compatibility problems and no extra installation process required for school users. It is time saving for teachers in schools. The special "Action Script" in Flash is used for simulated the states of particle motion. The students' learning motivation is highly involved, since the function of vector graph drawling of FLASH made the teaching software much more beautiful in front of students. During the teaching by this courseware, teacher can highlight the important part of concepts in the computer flexibly. 


\section{Results and Discussion}

\section{The Main Misconceptions of Particulate Nature in a Gaseous Phase}

\section{The distribution of gas particles in a closed system}

First, each student was asked to describe the nature of random distribution of gas, and we analyzed the students' spontaneous descriptions. We found that the spontaneous descriptions referred to either macroscopic properties or microscopic properties. At the beginning, it seemed that $75.68 \%$ students could answer the paper-and-pencil questions about distribution of particle with a homogeneous characteristic. When we tried to ask students both to describe by explanation and to draw the nature of gas particles, it showed that only $47.97 \%$ students of all subjects could correctly think both in answer and in explanation that particles of air were distributed homogeneously in all space of the bottle. It means that only one category in this section, micro-particulate description, arose which offered a correct explanation based on a particle view of gas. For those who could not answer correctly, invoke both macro and micro explanations. The wrong categories were used for explanation that did not correctly describe the particulate nature of gas. The results of this analysis were summarized in Table 2. The chi-square test of the categories of particle distributions among all grade levels indicated that it was significant statistically $(\mathrm{p}<.001)$. It indicated that students' abstract conception of particle distribution was growth with the age levels. It had some relationship with students' cognitive development.

Table 2 The students' responses about the distribution of particles as the position of the container is changed

\begin{tabular}{|c|c|c|c|c|c|c|}
\hline $\begin{array}{l}\text { categories of particle distribution and } \\
\text { the position of container }\end{array}$ & $\begin{array}{l}\text { no of subject } \\
\text { /percentage }\end{array}$ & Grade 5 & Grade 6 & Grade 7 & Grade 8 & Total \\
\hline $\begin{array}{l}\text { Gas distributed homogeneously in the whole } \\
\text { container, and is INDEPENDENT on the position }\end{array}$ & no of subject & 28 & 27 & 41 & 46 & 142 \\
\hline of the bottle & $\%$ & 38.89 & 37.50 & 53.95 & 60.53 & 47.97 \\
\hline $\begin{array}{l}\text { Gas was NOT distributed homogeneously } \\
\text { in the whole container, and is INDEPENDENT }\end{array}$ & no of subject & 19 & 28 & 23 & 20 & 90 \\
\hline on the position of the bottle & $\%$ & 26.39 & 38.89 & 30.26 & 26.32 & 30.41 \\
\hline $\begin{array}{l}\text { Gas distributed homogeneously in the whole } \\
\text { container, and is DEPENDENT on the position }\end{array}$ & no of subject & 14 & 4 & 4 & 3 & 25 \\
\hline of the bottle & $\%$ & 19.44 & 5.56 & 5.26 & 3.95 & 8.45 \\
\hline $\begin{array}{l}\text { Gas was NOT distributed homogeneously } \\
\text { in the whole container, and is DEPENDENT }\end{array}$ & no of subject & 11 & 13 & 8 & 7 & 39 \\
\hline on the position of the bottle & $\%$ & 15.28 & 18.06 & 10.53 & 9.21 & 13.18 \\
\hline $\begin{array}{l}\text { Gas was NOT distributed homogeneously } \\
\text { in the whole container, and is INDEPENDENT }\end{array}$ & no of subject & 72 & 72 & 76 & 76 & 296 \\
\hline on the position of the bottle & $\%$ & 100.00 & 100.00 & 100.00 & 100.00 & 100.00 \\
\hline
\end{tabular}

Chi-square $=136.827 \quad \mathrm{p}<.001$

As one-half numbers of gas particles was withdrawn from the bottle in a static closed system, percent of students' correct response about the distribution questions, without concerning the reasoning of the answer, was decreased from $75.68 \%$ to $63.18 \%$. It means that students did not really understand the meaning that particles were occupied more space at this situation. And among those incorrect responses, the percent of particles concentrated around the side of bottle was the most answers given by students. They thought that if all the particles occupied in the bottle, it would be distributed homogeneously. When one-half particle left, there was more space, and particles could easily stay in any place of the bottle. And among those incorrect responses, most stu- 
dents' reasoning was that weight of gas particles was very light, and they always went to the top part of container as the position of bottle was changed (as Case 3 in Figure 6). Some gas particle was heavier, they were not distributed homogeneously in the container, and therefore they stayed in the bottom of the container (as Case 5 in Figure 6). The fully shaded drawing as in Case1 (Figure 6) was categorized as continuous nature and random distribution.

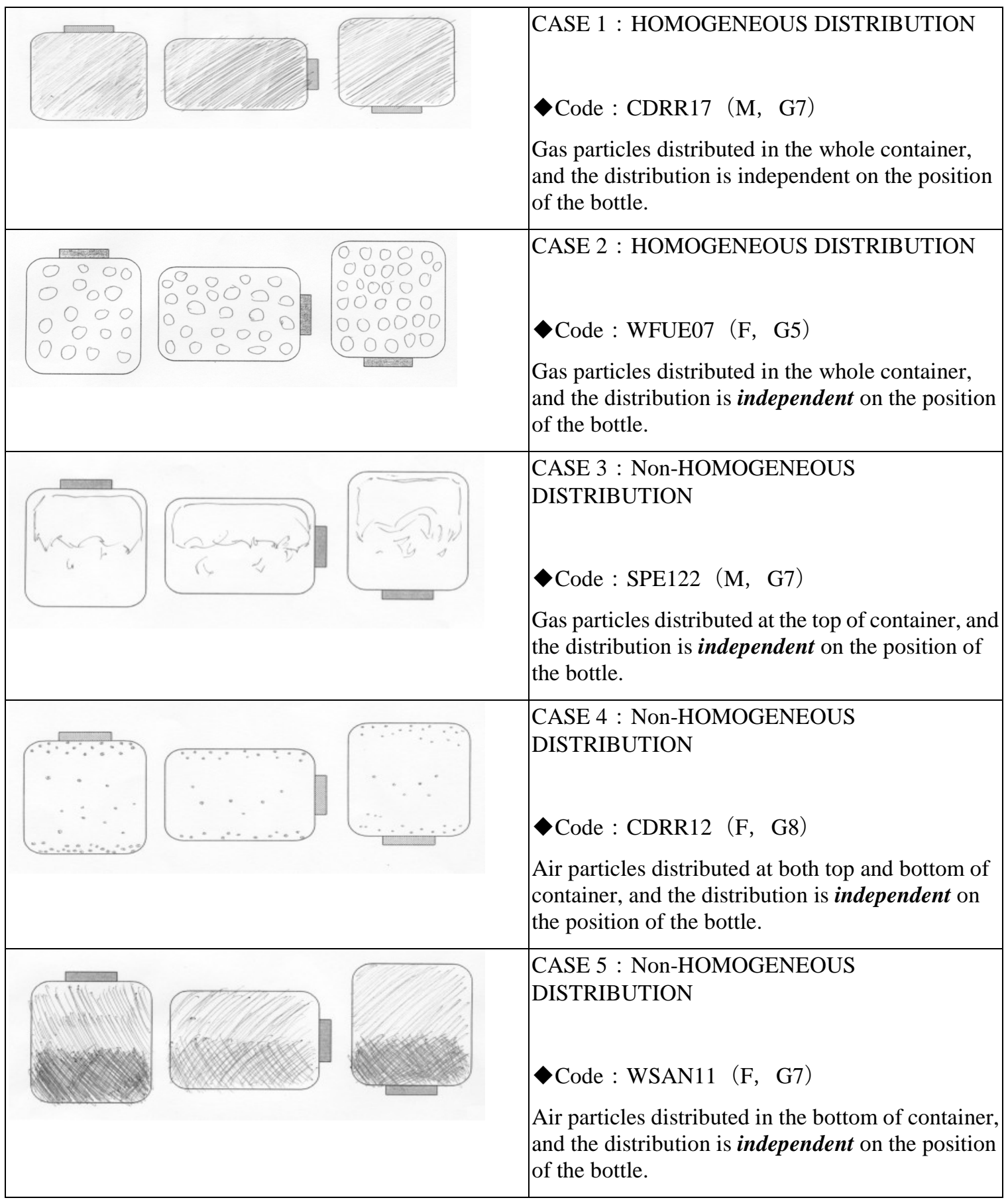




\begin{tabular}{|l|l|}
\hline Figure 6. Representations of students' \\
in a closed system with different bottle positions
\end{tabular}

\section{Particle concepts in a mixture of two kinds of gases}

For a mixture of two kinds of gases, $63.51 \%$ subjects could correctly answer paper-and-pencil questions that gases could occupied the whole space, and $63.18 \%$ students hold the correct conceptions that particles could mix homogeneously in the space. Students' answers concerning both homogeneous distribution and homogeneous mixing were classified as shown in Table 3 . The results indicated that there was a significant difference between these concepts and grade levels (chi-square $=157.249, \mathrm{P}<.001$ ). It revealed that only $48.65 \%$ of all students could correctly answer both the distribution and the mixing status of particles in a closed space.

Four types of results about the distribution of particles in a container and the mixing status of two kinds of gases were also explored by students' drawing as shown in Figure 7. There were $14.53 \%$ students had the idea of homogeneous mixing of two kinds of gases, but all the space was not occupied by these two kinds of gases. It also showed that $14.86 \%$ students thought that these two

Table 3 The particle distribution of a mixture with two kinds of gases

\begin{tabular}{lcrrrrr}
\hline \multirow{2}{*}{ CATEGORIES OF RESPONSE } & subjects & \multicolumn{7}{c}{ GRADE } \\
\cline { 2 - 8 } & $\%$ & 5 & 6 & 7 & 8 & Total \\
\hline 1.homogeneous distribution and & $\mathrm{n}$ & 38 & 23 & 36 & 47 & 144 \\
homogeneous mixture & $\%$ & 52.78 & 31.94 & 47.37 & 61.84 & 48.65 \\
\hline 2.NON-homogeneous distribution & $\mathrm{n}$ & 12 & 17 & 5 & 9 & 43 \\
and homogeneous mixture & $\%$ & 16.67 & 23.61 & 6.58 & 11.84 & 14.53 \\
\hline 3.homogeneous distribution and & $\mathrm{n}$ & 11 & 9 & 16 & 8 & 44 \\
NON-homogeneous mixture & $\%$ & 15.28 & 12.50 & 21.05 & 10.53 & 14.86 \\
\hline 4.NON-homogeneous distribution & $\mathrm{n}$ & 11 & 23 & 19 & 12 & 65 \\
and NON-homogeneous mixture & $\%$ & 15.28 & 31.94 & 25.00 & 15.79 & 21.96 \\
\hline \multicolumn{1}{c}{ Total } & $\mathrm{n}$ & 72 & 72 & 76 & 76 & 296 \\
\hline Chi-square $=157.249$ & $\mathrm{p}<.001$ & & & & &
\end{tabular}

Chi-square $=157.249 \quad \mathrm{p}<.001$ 
kinds of gases would not mix with each other, but they would occupy the entire space. We found that $21.96 \%$ students even did not have the idea of homogeneous mixing and homogeneously distribution of two kinds of particles. All of these students' conceptions were not well developed.

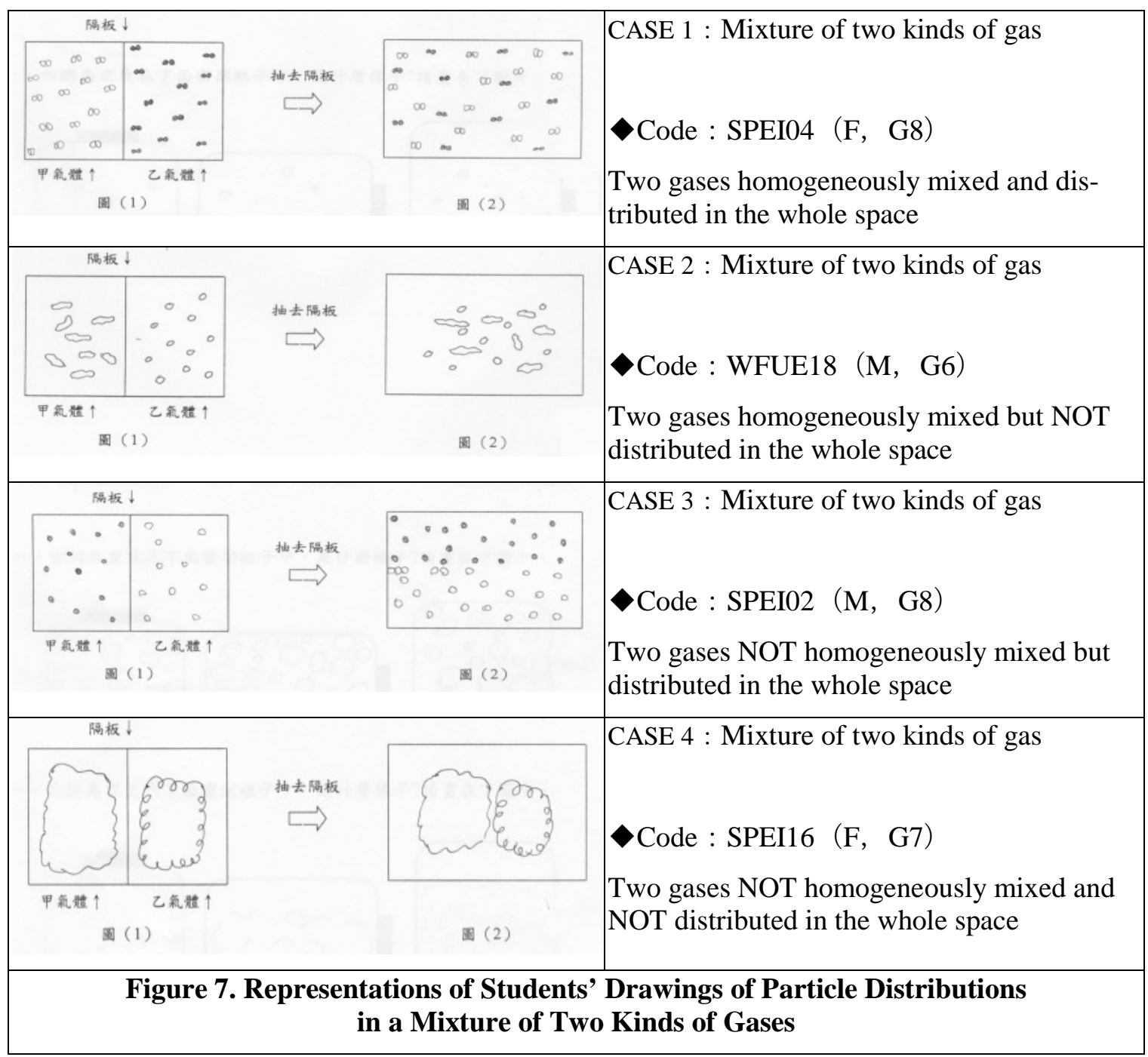

Table 4 Students' response and explanation about the motion of air particles in a closed system

\begin{tabular}{|c|c|c|c|c|c|c|c|}
\hline $\begin{array}{l}\text { Motion o } \\
\text { Particle } \\
\end{array}$ & & $\begin{array}{r}\text { No extra } \\
\text { force }\end{array}$ & $\begin{array}{l}\text { Effect by Space } \\
\text { in the bottle }\end{array}$ & $\begin{array}{r}\text { Particle can } \\
\text { move in space }\end{array}$ & $\begin{array}{l}\text { Gas always moves } \\
\text { out of the bottle }\end{array}$ & Other & Total \\
\hline \multirow[t]{2}{*}{ NO } & $\mathbf{n}$ & 52 & 30 & & & 1 & 83 \\
\hline & $\%$ & 62.65 & 36.14 & & & 1.20 & 28.04 \\
\hline \multirow[t]{2}{*}{ YES } & $n$ & 5 & 25 & 113 & 56 & 14 & 213 \\
\hline & $\%$ & 2.35 & 11.74 & 53.05 & 26.29 & 6.57 & 71.96 \\
\hline \multirow[t]{2}{*}{ TOTAL } & $\mathbf{N}$ & 57 & 55 & 113 & 56 & 15 & 296 \\
\hline & $\%$ & 19.26 & 18.58 & 38.18 & 18.92 & 5.07 & 100.00 \\
\hline
\end{tabular}

Chi-square $=201.211 \quad \mathrm{P}<.001$ 


\section{The dynamic motion of gas particles in a closed system}

From the traditional method of students' drawing of the particles, we could not get students' concepts of particle in motion; therefore, in this part we also used a two-tier test. The students' answers and reasoning were involved in scoring as shown in Table 4. Only 38.18\% students could answer the problems with correct explanation. It indicated that the concepts of the motion of particles in a closed system existed a significant relationship between the answers and explanations (Chi-square $=201.211, \mathrm{p}<.001)$.

\section{Temperature and the particulate concepts}

From the textbooks, students learn that as temperature changes, it will change the rate of particulate motion, therefore it will also increase the pressure of gases. For understanding these conceptions, students should have the conceptions of particle distribution and kinetic motion in space. Students' answers and reasoning of the effect of temperature on particles were indicated in Table 5. "Heating made expansion or cooling made withdrawing" was the basic concept taught in school. Students used this concept from macroscopic view to explain the microscopic effect of heating on particles. Their popular misconception in explanation of temperature effect on particles was "Heating made individual particle expansion or cooling made individual particle shrinking". Therefore, only $9.46 \%$ of all subjects could answer and explain correctly.

Table 5 Students' responses of the temperature effect on particle of air (increased temperature)

\begin{tabular}{llrrrrrrr}
\hline Responses & & $\mathrm{A}$ & $\mathrm{B}$ & $\mathrm{C}$ & $* \mathrm{D}$ & $\mathrm{E}$ & $\mathrm{F}$ & Total \\
\hline move upward* & $\mathrm{N}$ & 63 & 123 & 12 & 28 & 51 & 2 & 279 \\
& $\%$ & 21.28 & 41.55 & 4.05 & 9.46 & 17.23 & 0.68 & 94.26 \\
\hline move downward & $\mathrm{N}$ & 8 & 2 & 1 & 1 & 1 & & 13 \\
& $\%$ & 2.7 & 0.68 & 0.34 & 0.34 & 0.34 & & 4.39 \\
\hline can not move & $\mathrm{N}$ & 1 & 1 & & & & 1 & 3 \\
& $\%$ & 0.34 & 0.34 & & & & 0.34 & 1.01 \\
\hline uncertain & $\mathrm{N}$ & & & & & & 1 & 1 \\
& $\%$ & & & & & & 0.34 & 0.34 \\
\hline Total: & $\mathrm{N}$ & 72 & 126 & 13 & 29 & 52 & 4 & 296 \\
& $\%$ & 24.32 & 42.57 & 4.39 & 9.8 & 17.57 & 1.35 & 100 \\
\hline
\end{tabular}

chi-square $=339.766, \mathrm{P}<.001$

Students' $\mathrm{A}=$ expand as temperature increased, withdraw as temperature decreased

Explanations: $\quad \mathrm{B}=$ hot air going up, cool air settle down

$\mathrm{C}=$ heating cause the amount of gas increased as heating

$* \mathrm{D}=$ heating increased the motion rate of gas and also increased the gas pressure

$\mathrm{E}=$ produced heat can push gas moving, then push water moving

$\mathrm{F}=$ others

\section{The Conception of the Characteristic of Gas Particles}

The drawings students made for the bottle section of the particulate test were quite similar to the diagrams reported by Novick and Nussbaum (1978). Most students filled in the bottle with various kinds of marks that were quite obviously either continuous or particulate in nature. The gas bottle diagrams in Figure 8 represent the majority of students' drawings. Nearly every drawing could be placed in one of the following categories: continuous nature, pseudo- particulate nature, or particulate nature. The continue nature can be subdivided into long line, short line, lump, and long arrow, and the pseudo-particulate nature can be divided into short arrow or small unit. Table 6 indicates that only $17.23 \%$ of all the subjects could correctly drew the particulate nature of gas in a 
bottle. A much greater number of the students exhibited characteristics of a macro-particulate explanatory framework. Within this group there was also a great deal of variability, and the students ranged from nearly all macro-continuous views of gas to a much more macro-particulate view of gas. There was a statistically significant difference between the particulate nature and the grade levels (chi-square $=136.827, \mathrm{p}<.001$ ).

\begin{tabular}{|c|c|c|c|c|}
\hline Code & & nple & Description & CASE \\
\hline $\begin{array}{l}\text { LL } \\
\text { Long } \\
\text { line }\end{array}$ & & & $\begin{array}{l}\odot \text { long line as gas particles } \\
\odot \text { long curve as gas particles }\end{array}$ & 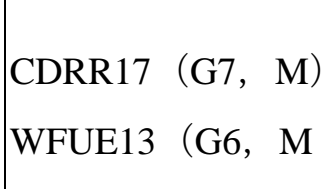 \\
\hline $\begin{array}{l}\text { SL } \\
\text { Short } \\
\text { line }\end{array}$ & & & 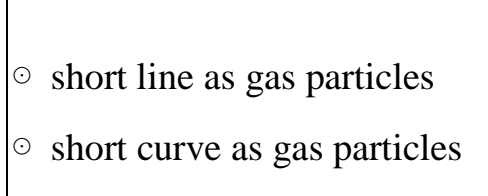 & 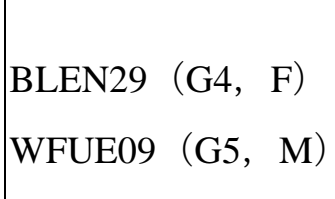 \\
\hline $\begin{array}{l}\text { BB } \\
\text { lump }\end{array}$ & & & $\begin{array}{l}\odot \text { a whole lump as gas parti- } \\
\text { cles }\end{array}$ & $\begin{array}{l}\text { DSUI14（G8, M) } \\
\text { ZCHN16（G6, F })\end{array}$ \\
\hline $\begin{array}{l}\text { LA } \\
\text { Long } \\
\text { arrow }\end{array}$ & & & $\odot$ long arrows as gas particles & $\begin{array}{l}\text { WSAN06（G7, M) } \\
\text { BLEN14（G6, F })\end{array}$ \\
\hline $\begin{array}{l}\text { SA } \\
\text { Short } \\
\text { arrow }\end{array}$ & & & $\odot$ short arrows as gas particles & 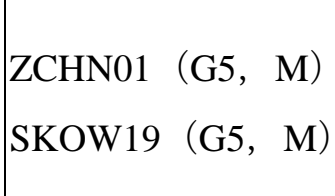 \\
\hline $\begin{array}{l}\text { PS* } \\
\text { Particle }\end{array}$ & & 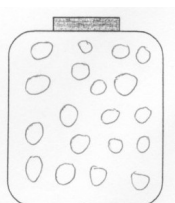 & $\begin{array}{l}\text { CORRECT DRAWING } \\
\odot \text { same size of particles as gas } \\
\text { particles }\end{array}$ & $\begin{array}{l}\text { DSUI13 }(\mathrm{G} 8, \mathrm{~F}) \\
\text { WFUE07 }(\mathrm{G} 5, \quad \mathrm{~F})\end{array}$ \\
\hline
\end{tabular}




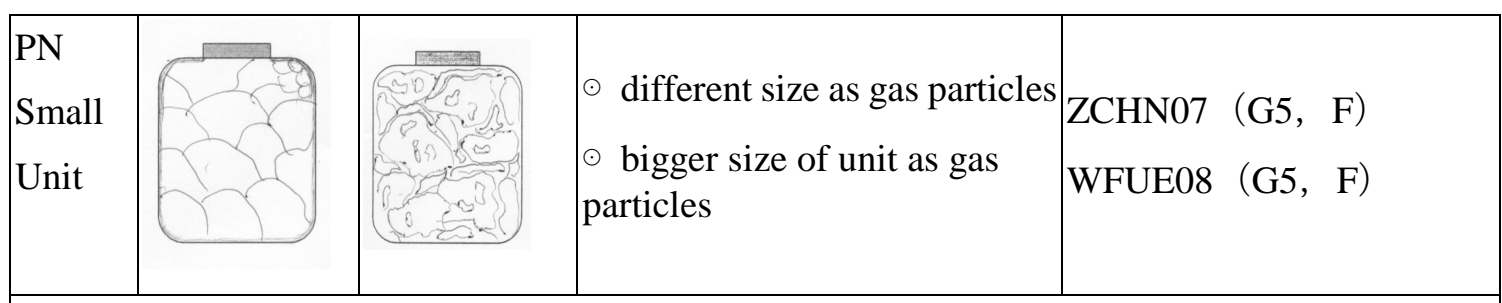

Figure 8. Categories of students' representation of drawing the particles in a closed bottle

Table 6 The categories of drawings made by students for the particulate concepts in a closed system

\begin{tabular}{|c|c|c|c|c|c|c|}
\hline Categories & subject / \% & Grade 5 & Grade 6 & Grade 7 & Grade 8 & Total \\
\hline \multirow{2}{*}{ BB } & $\mathrm{n}$ & 4 & 14 & 10 & 7 & 35 \\
\hline & $\%$ & 5.56 & 19.44 & 13.16 & 9.21 & 11.82 \\
\hline \multirow{2}{*}{$\begin{array}{l}\text { LA } \\
\text { long arrow } \\
\end{array}$} & $\mathrm{n}$ & 4 & 4 & 2 & & 10 \\
\hline & $\%$ & 5.56 & 5.56 & 2.63 & 0.00 & 3.38 \\
\hline \multirow{2}{*}{$\begin{array}{l}\text { LL } \\
\quad \text { long line } \\
\end{array}$} & $\mathrm{n}$ & 27 & 32 & 37 & 13 & 109 \\
\hline & $\%$ & 37.50 & 44.44 & 48.68 & 17.11 & 36.82 \\
\hline \multirow{2}{*}{$\begin{array}{l}\mathrm{PN} \\
\text { small unit } \\
\end{array}$} & $\mathrm{n}$ & 11 & 5 & 4 & 15 & 35 \\
\hline & $\%$ & 15.28 & 6.94 & 5.26 & 19.74 & 11.82 \\
\hline \multirow{2}{*}{$\begin{array}{l}\text { PS* } \\
\text { particulate } \\
\end{array}$} & $\mathrm{n}$ & 8 & 7 & 6 & 32 & 51 \\
\hline & $\%$ & 11.11 & 9.72 & 7.89 & 42.11 & 17.23 \\
\hline \multirow{2}{*}{$\begin{array}{l}\text { SA } \\
\text { short arrow }\end{array}$} & $\mathrm{n}$ & 11 & 3 & 7 & 2 & 23 \\
\hline & $\%$ & 15.28 & 4.17 & 9.21 & 2.63 & 7.77 \\
\hline \multirow{2}{*}{$\begin{array}{l}\text { SL } \\
\text { short line } \\
\end{array}$} & $\mathrm{n}$ & 9 & 7 & 10 & 7 & 33 \\
\hline & $\%$ & 12.50 & 9.72 & 13.16 & 9.21 & 11.15 \\
\hline \multirow[t]{2}{*}{ Total } & $\mathrm{n}$ & 72 & 72 & 76 & 76 & 296 \\
\hline & $\%$ & 100.00 & 100.00 & 100.00 & 100.00 & 100.00 \\
\hline
\end{tabular}

chi-square $=136.827, \mathrm{p}<.001$

\section{Teaching Effect through a Computer Simulated Demonstration}

In concerning the number conservation of particles, distribution of particles, dynamic motion of particles, and pressure change of particles, we designed a computer simulation strategy used for teaching. After teaching there were a comparison between pre-test and post-test of these concepts. The effectiveness of the strategy of instruction was indicated by the significant difference between the percentage of correct answers between pre-test and post-test. The percentages of correct responses in post-test were significantly higher than that in the pre-test at the .001 level (Figure 9). 

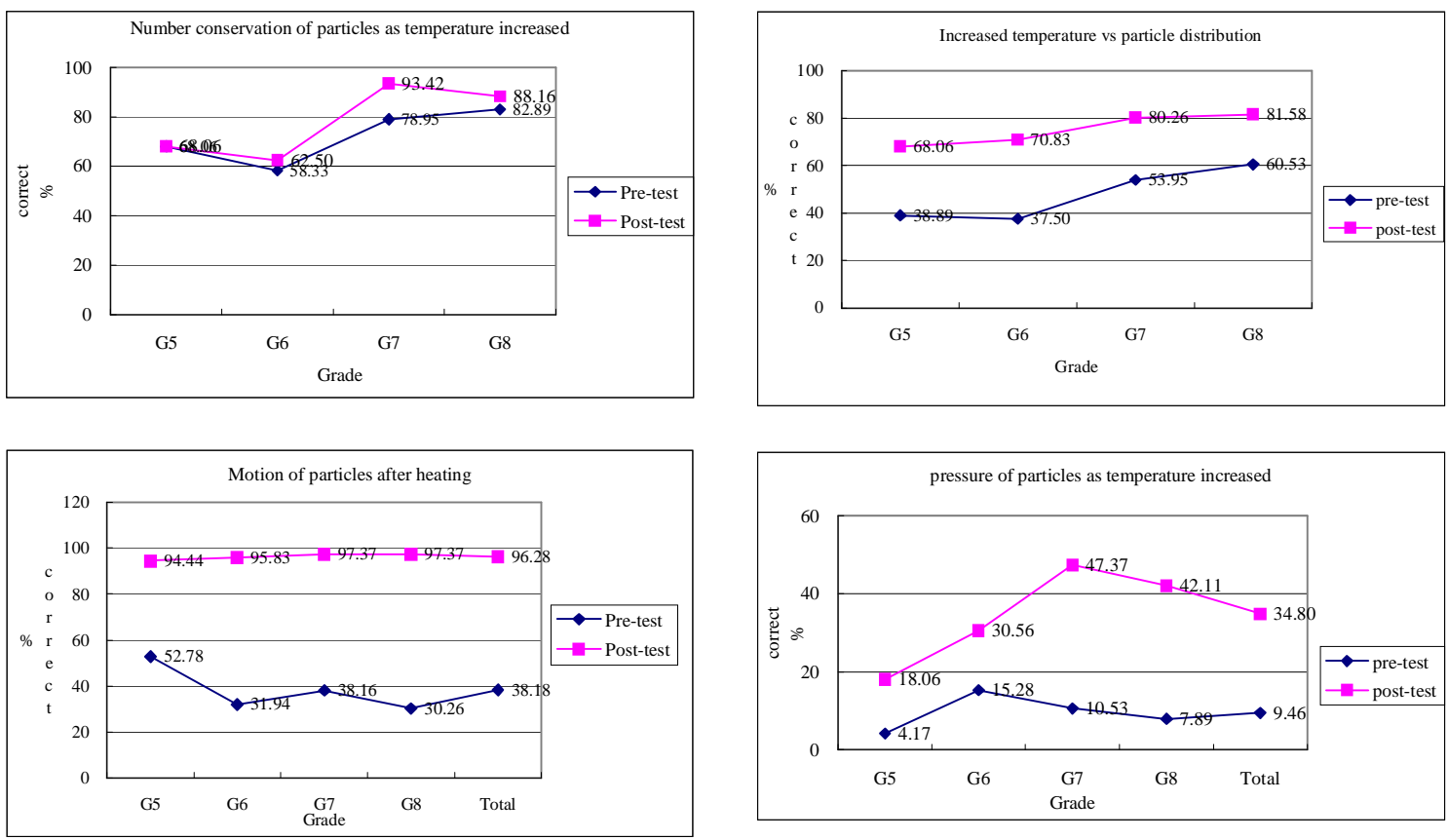

Figure 9 A comparison of students' conceptual changes of particles in pre-test and post-test by using computer simulation demonstration in teaching

This significant difference in favor of the post-test indicated that instructional techniques, with a computer simulation demonstration, enable the student to acquire the desired objectives of the instruction. The significant difference in favor of students using computer simulation demonstration may be attributed to three factors: (1) The simulation more closely approximated the desired particulate phenomenon. (2) The simulation was more flexible and easier to manipulate by teacher or students than the laboratory equipment used in classroom. (3) The simulation with computer made abstract concepts in science more concrete for students' understanding, and the cognitive conflict based activity provided students' conceptual change more easily.

\section{Conclusion and Discussion}

In this study, from the results of particulate conception test with drawing and two-tier format which was devised to test misconceptions concerning the nature of gas particles, it showed that students apparently perceived the gas as a continuous medium, rather than as an aggregation of particles. Therefore, it could be the reasons for students to have misconception of gases. Many students also hold a static rather than kinetic conception of the particulate model of gas. In other words, even though they have learned it in school, the particulate theory does not become useful for most of the students. This is the reason why the students can not correctly learn the related science concepts. In view of those findings, it was shown that the existence and persistence of students' misconceptions about the particulate nature of gases is an important factor to be considered in the teaching of the principles or theories of the particulate conceptions related to gases. According to Piaget, the particulate concept is classified as stage of formal operations, and a student should enter the formal operational stage at about age 11 (Flavell, 1963). Why the problem with students of age 12-15? The answer is that relatively few students are at the intellectual level expected according to Piaget's age levels. 
It indicated that to teach the term knowledge was not enough in school. It should emphasize the relationships and links on the new knowledge and the preconception or misconceptions held by the students. In this research, after the instruction with a cognitive conflict and conceptual change teaching curriculum which was developed to stimulate learners to generate modifications of their own pre-exiting concept concerning the particulate nature of gas, the students did demonstrate significant improvement on the post-test concerning particulate concepts.

High school chemistry instruction is challenging for both the students and the teacher. There is a wide range of skills and abilities, which are required for students to comprehend the course material; for example, students, need spatial ability to comprehend kinetic motion of gas particles, atomic structure, or molecular configuration. One challenge for the teachers is in the using of teaching technology they required for the wide variation of students in abilities and skills. By comparison of the scores of post-test and pre-test, the improvement after teaching implied that this teaching by computer simulation obviously helped some students understand the related concepts of particulate theory. If teaching strategies to overcome misconceptions are to be effective, then they must be appropriate to the particular misconception prevalent at each operational stage. It would seem, from the results of this study, that the three dimensional simulation structures in computer program are much more confident with the concepts of gas, and also with the way evidence can be used to construct explanations for students.

To select an accurate model of particulate concepts for teaching gas behavior is difficult, since all models of scientific phenomena are approximate. To design the simulation of particle behavior with FLASH software is a good practical way for designing the teaching units. It is a better way to link students' existing misconceptions and scientists' concepts. Therefore, it is a useful scientific model for students' explaining scientific concepts from microscopic point of view.

The recent research concerns the impact of a teacher's beliefs about instruction on the use of technology in the classroom. To understand the role computers play in changes to instructional practice, we should pay much attention upon what is already established in the study of student cognitive development. We should also frame teachers as main agents for change in teaching practice. We conclude that using computers in the science classroom in a constructivist perspective is one of the best teaching strategy for teacher's decision. While testing our instructional unit we confirmed for ourselves the idea that interactive graphics computer packages can be very effective in the teaching of abstract concepts in science such particulate nature. In particular they can be an effectual remedy against some students' misconceptions on particulate concepts.

\section{Acknowledgement}

Financial support provided by the National Science Council of the ROC (Grant NSC91-2511-S-003-079) is gratefully acknowledged.

\section{References}

Alessi, S.M., \& Trollip, S. R. (1991). Computer-based instruction: Methods and development. NJ: Prentice Hall.

Benson, D. L. (1993). Students' preconceptions of the nature of gases. Journal of Research in Science Teaching, 30 (6), 587-597.

Borghi, L., De Ambrosis, A., Massara, C. I., Grossi, M. G., \& Zoppi, D. (1988). Knowledge of air: A study of children aged between 6 and 8 years. International Journal of Science Education, 10 (2), 179-188.

Dexter, S. L., Anderson, R. E., \& Becker, H. J. (1999). Teachers' views of computers as catalysts for changes in their teaching practice. Journal of Research on Computing in Education, 31 (3), 221-239. 
Flavell, J. (1963). The Developmental Psychology of Jean Piaget. D. Van Nostrand Company.

Furio, C. J., Perez, J. H., \& Harris, H. H. (1987). Parallels between adolescents' conception of gases and the history of chemistry. Journal of Chemical Education, 64 (7), 616-618.

Gabel, D. L., Samuel, K. V., \& Hunn, D. (1987). Understanding the particulate nature of matter. Journal of Chemical Education, 64 (8), 695-697.

Gagne, R.M., Wager, W. \& Rojas, A.(1981). Planning and authoring computer-assisted instruction lessons. Educational Technology, 21, 17-26.

Griffiths, A. K., \& Preston, K. R.(1992). Grade-12 students' misconceptions relating to fundamental characteristics of atoms and molecules. Journal of Research in Science Teaching, 29 (6), 611-628.

Hwang, B. T. (1998, August 9-14). What are the eight grade students learnt in some chemical concepts in Taiwan. Paper presented at IUPAC, $15^{\text {th }}$ International Conference on Chemical Education. Ain Shams University, Cairo, Egypt.

Iding, M. K. (2000). Is seeing believing? Features of effective multimedia for learning science. International Journal of Instructional Media, 27 (4), 403-415.

Johnson, P. (1998a). Progression in children's understanding of a 'basic' particle theory: a longitudinal study. International Journal of Science Education, 20 (4), 393-412.

Johnson, P. (1998b). Children's understanding of changes of state involving the gas state, Part 1 : Boiling water and the particle theory. International Journal of Science Education, 20 (5), 567-583.

Krendl, K.A., \& Lieberman, P.A. (1988). Computers and learning: A review of recent research. Journal of Educational Computing Research, 4 (4), 367-399.

Mayer, R.E., \& Moreno, R. (1998). A split-attention effect in multimedia learning: Evidence for dual information processing systems in working memory. Journal of Educational Psychology, 90, 312-320.

Mayer, R.E. (1999). When multimedia works: Designing multimedia for meaningful learning. Paper presented at the Annual Meeting of the American Educational Research Association.

Newton, D. M. (1999). Pressure, pressure everywhere. Science and Children, 36 (8), 34-37.

Nussbaum, J. (1997). History and philosophy of science and the preparation for constructivist teaching: the case of particle theory. In J.J. Mintzes, J.H. Wandersee, \& J.D.Novak (Eds.), Teaching science for understanding: A human constructivist view (pp165-194). San Diego: Academic Press.

Novick, S., \& Nussbaum, J. (1978). Junior high school pupils' understanding of the particulate nature of matter: An interview study. Science Education, 62 (3), 273-281.

Novick, S., \& Nussbaum, J. (1981). Pupils' understanding of particulate nature of matter: a cross-age study. Science Education, 65 (2), 187-196.

Rieber, L. P. (1996). Animation as feedback in a computer-based simulation: Representation matters. $E T R \& D, 44(1), 5-22$.

Rowell, J.A., \& Dawson, C.J. (1981). Volume, conservation and instruction: a classroom based Solomon four group study of conflict. Journal of Research in Science Teaching, 18 (6), 533-545.

Stavy, R. (1988). Children's conception of gas. International Journal of Science Education, 10 (5), 553-560.

Tytler, R. (1998b). Children's conceptions of air pressure: exploring the nature of conceptual change. International Journal of Science Education, 20 (8), 929-958.

Williamson, V., \& Abraham, M. (1995). The effects of computer animation on the particulate mental models of college chemistry students. Journal of Research in Science Teaching, 32, 521-534. 


\section{Biographies}

Bao-tyan Hwang. Professor (1989-); B.Sc. in Chemistry, National Taiwan Normal University (1965); M.Sc. Vanderbilt University (1977); Ph.D. Candidate, Vanderbilt University (1982); Visiting Academic, University of London (1996); Editor, Editorial Board of Proceeding (Part D) of the National Science Council, ROC (1996-1998); Member of Science Education Proposal Evaluation Committee of the National Science Council, ROC (1996-1998). Editor of Physical Science Textbooks for High Schools, Editorial Board of the National Institute for Compilation and Translation, ROC (1997-2004). Research fellowships of National Science Council, ROC (1987-2000). My research interests focus on: (1) Diagnosis and teaching strategies of science concepts; (2) Cognitive development and science education; (3) Teachers' education: Teaching Competency of Preserves Teachers.

Shang-feng Chiu. B.Sc. in Chemistry, National Chung Cheng University (1999); M.Sc. Chemistry Department, National Taiwan Normal University (2002). Chemistry Teacher in Chien Kuo Senior High School in Taipei (2002-2003). Service as Lieutenant in Army of Taiwan, ROC (2003-2005). 